\title{
Functional outcomes and quality of life after a 6-month early intervention program for oral cancer survivors: a single-arm clinical trial
}

\author{
Yueh-Hsia Chen ${ }^{1}$ ， Wei-An Liang ${ }^{1}$ ， Chung-Yin Hsu ${ }^{2}$ ， Siang-Lan Guo ${ }^{1}$ ， Shwu-Huei Lien ${ }^{1}$, Hsiao-Jung Tseng ${ }^{3}$ \\ , Yuan-Hung Chao Corresp. 2, 4,5 \\ 1 Rehabilitation Center, Department of Plastic and Reconstructive Surgery, Chang Gung Memorial Hospital Linkou Branch, Taoyuan, Taiwan \\ 2 School and Graduate Institute of Physical Therapy, College of Medicine, National Taiwan University, Taipei, Taiwan \\ 3 Center for Big Data Analytics and Statistics, Chang Gung Memorial Hospital Linkou Branch, Taoyuan, Taiwan \\ 4 Rehabilitation Center, National Taiwan University Hospital Chu-Tung Branch, Hsinchu County, Taiwan \\ 5 Center of Physical Therapy, National Taiwan University Hospital, Taipei, Taiwan \\ Corresponding Author: Yuan-Hung Chao \\ Email address: yuanhungchao@ntu.edu.tw
}

Background. Advanced treatment of oral cancer increases survival rates; however, it also increases the risk of developing shoulder dysfunction, dysphagia, oral dysfunction, donor site morbidity and psychological issues. This single-arm preliminary pilot study aims to explore the effects of a 6-month early intervention program following reconstructive surgery in oral cancer survivors. Methods. A total of 65 participants were analyzed following reconstructive surgery. Outcome measurements were taken during the first visit, and at one, three and six months after reconstructive surgery. Results. Scapular muscle strength and shoulder range of motion progressively improved during the 6-month followup. The mean Disability of the Arms, Shoulder and Hand (DASH) score showed significant improvement at 1 month $(p<.001)$. Health related QoL showed significant differences between baseline and 6-months post-surgery scores on global health and on most of the function and symptom scales. The predicted return-to-work rate was $80 \%$ at 1 year after the operation. Return-to-work rate differs in different vocational types, with a higher rate of return in the skilled or semi-skilled (87.5\%) and self-employed (86.7\%). Conclusions. We suggest that early integrated intervention program with a follow-up of at least 6 months following reconstructive surgery may help develop and identify intervention guidelines and goals in the initial 6 months of treatment following neck dissection in oral cancer survivors. 
1 Title: Functional outcomes and quality of life after a 6-month early intervention program

\section{2 for oral cancer survivors: a single-arm clinical trial}

4 Yueh-Hsia Chen ${ }^{1}$, Wei-An Liang ${ }^{1}$, Chung-Yin $\mathrm{Hsu}^{2}$, Siang-Lan Guo ${ }^{1}$, Shwu-Huei Lien ${ }^{1}$, Tseng

5 Hsiao-Jung 3 , Yuan-Hung Chao $2,4,5$

6

$7 \quad{ }^{1}$ Rehabilitation Center, Department of Plastic and Reconstructive Surgery, Chang Gung Memorial

8 Hospital, Taoyuan, Taiwan.

$9{ }^{2}$ School and Graduate Institute of Physical Therapy, College of Medicine, National Taiwan

10 University, Taipei, Taiwan.

$11{ }^{3}$ Center for Big Data Analytics and Statistics, Chang Gung Memorial Hospital, Taoyuan, Taiwan.

$12{ }^{4}$ Rehabilitation Center, National Taiwan University Hospital Chu-Tung Branch, Hsinchu County,

13 Taiwan.

$14{ }^{5}$ Center of Physical Therapy, National Taiwan University Hospital, Taipei, Taiwan. 
16 To whom correspondence should be addressed:

17 Yuan-Hung Chao, Ph.D., PT

18 Assistant Professor

19 School and Graduate Institute of Physical Therapy, College of Medicine, National Taiwan

20 University

21 Rm. 324, 3F., No. 17, Xuzhou Rd., Zhongzheng Dist., Taipei City 10055, Taiwan

22 Tel: +886-2-3366-8129

23 Fax: +886-2-3366-8161

24 E-mail: yuanhungchao@,ntu.edu.tw

25

26 


\section{ABSTRACT}

28 Background. Advanced treatment of oral cancer increases survival rates; however, it also increases

29 the risk of developing shoulder dysfunction, dysphagia, oral dysfunction, donor site morbidity and

30 psychological issues. This single-arm preliminary pilot study aims to explore the effects of a 6-

31 month early intervention program following reconstructive surgery in oral cancer survivors.

32 Methods. A total of 65 participants were analyzed following reconstructive surgery. Outcome

33 measurements were taken during the first visit, and at one, three and six months after reconstructive

34 surgery.

35 Results. Scapular muscle strength and shoulder range of motion progressively improved during

36 the 6-month follow-up. The mean Disability of the Arms, Shoulder and Hand (DASH) score

37 showed significant improvement at 1 month $(p<.001)$. Health related QoL showed significant

38 differences between baseline and 6-months post-surgery scores on global health and on most of

39 the function and symptom scales. The predicted return-to-work rate was $80 \%$ at 1 year after the

40 operation. Return-to-work rate differs in different vocational types, with a higher rate of return in

41 the skilled or semi-skilled (87.5\%) and self-employed (86.7\%). 
42 Conclusions. We suggest that early integrated intervention program with a follow-up of at least 6

43 months following reconstructive surgery may help develop and identify intervention guidelines

44 and goals in the initial 6 months of treatment following neck dissection in oral cancer survivors.

45.

46

47 


\section{INTRODUCTION}

49 Oral cavity cancer is the 11th most common cancer in the world. Its incidence rate is highly

50 correlated with exposure to tobacco, betel nut chewing, and alcohol in developing nations, and the

51 incidence of human papillomavirus (HPV) infection in developed countries.(Krishna Rao et al.

52 2013; Marur \& Forastiere 2016; Sankaranarayanan et al. 2015) Advanced surgical technology in

53 oral cancer increases the survival rate, but the primary functions of the oral cavity-respiration,

54 speech, mastication, deglutition, and appearance - are significantly compromised. Impairments

55 include scar contracture or radiation-induced trismus, drooling, impaired mastication and

56 deglutition with a lip or tongue defect. In the advanced stage of cancer, donor-site-related

57 impairments often develop, such as accessory nerve shoulder dysfunction (ANSD).(Cappiello et

58 al. 2005; Dijkstra et al. 2001; Stuiver et al. 2008; van Wilgen et al. 2003) The probability of

59 shoulder dysfunction after neck dissection is as high as 70\%.(Carr et al. 2009; Dijkstra et al. 2001)

60 ANSD is manifested as impaired shoulder mobility and pain. Electromyography (EMG) studies

61 have shown significant increase in spinal accessory nerve denervation (Erisen et al. 2004) and

62 decreased trapezius muscle activity after neck dissection.(Lima et al. 2011; McGarvey et al. 2013a) 
63 Though the modified radical and selective neck dissections aims to reduce the prevalence of

64 shoulder dysfunction, a wide range of ANSD incidence rates after neck dissection have been

65 reported.(Sheikh et al. 2014; Umeda et al. 2010)

66 Health-related quality of life (QoL) has been extensively studied in oral cancer survivors to

67 identify the impact of the treatment-related morbidity and physical issues. This is used for newly

68 diagnosed oral cancer as well as recurrence. Recent studies have demonstrated that poor oral and

69 physical health-related QoL are found in oral cancer patients compared with the general

70 population.(Barrios et al. 2015) Shoulder dysfunction (decreased muscle strength, range of motion

$71[\mathrm{ROM}]$ and pain) is associated with decreased QoL.(McNeely et al. 2015) Postoperative radiation

72 therapy is associated with decreased global health, increased xerostomia and short term

73 fatigue(Ch'ng et al. 2014). Issues of oral function, such as swallowing, speech and social eating

74 ensue one year or more after the reconstructive surgery ${ }^{19}$. Poor role function and social function

75 are predicted in the advanced-stage oral cancer survivors as well.(Schliephake \& Jamil 2002) In

76 these, shoulder dysfunction, global health, oral function and social function would be the aim of

77 address in this study. 
78 Given the issues mentioned above, this study aims to explore changes in physical function and

79 self-perceived QoL in consequence of an early intervention program after oral cancer

80 reconstructive surgery. While most research focuses on a single measure of treatment outcome and

81 its effect on QoL, we assumed that a range of treatment outcome measures would affect health-

82 related quality of life, including symptoms, dysfunctions, and survival. Therefore, this research

83 aims to evaluate the outcomes of an early-intervention program (i.e., progressive resistance

84 exercise, soft-tissue massage, joint range of motion exercise, pain management and functional

85 training) by physical examination, QoL questionnaire and return-to-work status after oral cancer

86 reconstructive microsurgery through exploratory analyses. Through exploring the outcomes in the

87 early and the advanced stage population eligible for surgery, the results may help develop and

88 identify intervention guidelines and goals in the initial 6 months of treatment following neck

89 dissection in oral cancer survivors.

91 MATERIALS AND METHODS

92 This study was a single-arm preliminary pilot study. The participants were enrolled from January 
932015 to June 2016. The inclusion criteria were survival after excision of oral cavity squamous cell

94 carcinoma (SCC) with reconstructive microsurgery, and age between 20 and 65 years old. Patients

95 are recruited through the plastic surgeon's referral. Patients were excluded if they were identified

96 as cognitively impaired; having distant metastasis or recurrence; or unable to communicate or

97 comprehend the questionnaires. Written informed consent and verbal trial information was

98 provided and obtained from all participants. Informed consent for publication of identifying

99 images of study participants was also obtained. This study was conducted in the Chang Gung

100 Memorial Hospital in Taoyuan, Taiwan, and approved by the Chang Gung Medical Foundation

101 Institutional Review Board (Approval No: 103-5164B, 104-2300C, 104-8154C). The authors

102 declare that all methods were performed according to the relevant guidelines and regulations

103 established by the oversight boards and agencies.

104 Interventions started early after the reconstructive microsurgery. All participants underwent each

105 component of the intervention program, which consisted of pain management, scar management,

106 temporomandibular joint (TMJ) exercise, shoulder and neck exercise, and functional training of

107 the donor site and recipient site to restore oral and physical function. The intervention program 
108 was divided into 3 phases: (1) the early phase (within 1 month after operation), (2) the middle

109 phase (1 to 3 months post-operation), (3) and the late phase (more than 3 months post-operation).

110 Early phase: The early phase intervention initiated at an average of 8.3 days following

111 reconstructive surgery and lasted within 1-month post operation. In the early phase, the main goal

112 was to help the participants deal with the problems suffered (i.e., pain, edema, shoulder

113 dysfunction and strength loss, soft tissue tightness and functional limitation) as the result of the

114 surgery. The intervention consisted were as follows: 1) Transcutaneous Electrical Stimulation was

115 administered for $15 \mathrm{~min}$. per treatment session and the intensity was adjusted to patient's tolerance

116 to alleviate shoulder pain or soreness. 2) Gentle soft tissue mobilization and scar massage on the

117 donor and recipient sites was performed for 15 min. per treatment session and the intensity was

118 adjusted to patient's tolerance to prevent edema-induced stiffness. 3) To increase TMJ range of

119 motion, the participants were guided to exercise their TMJ during the first visit and to use tongue

120 depressors to assist in performing the TMJ exercise if needed in the following visits. 4) Active or

121 active-assistive exercises for neck, shoulder and donor site were performed for 10 repetitions in

122 each session. 5) The progressive shoulder resistance exercise consisted of closed-chain and open- 
123 chain exercises that were adjusted sequentially according to pain conditions (Fig 1). 6) In cases

124 involving fibular osteoseptocutaneous flap harvest, big toe flexion was avoided in the initial 6

125 weeks. 7) Functional training such as transfer, ambulation, and activities of daily living (ADL)

126 was administered before discharge from the hospital. All of these were initiated as soon as the

127 wound condition was stable (i.e. normal capillary refill decided by the surgeon clinically.) The

128 participants were instructed to perform self-massage and other ROM exercises hourly during

129 waking hours and was checked using exercise diaries kept by the participants. During the period

130 of hospitalization (average duration $=3$ weeks), participants received the intervention every

131 weekday for an average of $40 \mathrm{~min}$. per treatment session. The treatment program was administered

132 once a week after discharge from hospital.

133 Middle phase: The middle phase lasted from 1-3 months post operation. During this phase, the

134 goal was to focus on the impairment suffered (i.e. scar development, soft tissue tightness, shoulder

135 joint dysfunction and strength loss, functional limitation) from the surgery or radiation therapy

136 (RT). The participants attended the rehabilitation center for one-on-one therapy once per week.

137 The interventions included: 1) Scar massage was employed 5 to 10 minutes prior to other treatment 
138 programs. 2) Soft tissue massage and joint ROM exercise as described in the early phase was

139 implemented as well with intensity up to patient's tolerance. Once the participants felt free of

140 shoulder pain, the training was transferred to the open-chain exercise. 3) Progressive resistance

141 exercise (PRE) training for the open-chain exercises was administered with free weights or thera-

142 bands 1 set of 10 repetitions in one session (Fig 2). In this phase, some of the participants started

143 to receive RT, which can interfere with TMJ and oral function. 4) To maintain TMJ flexibility,

144 conventional therapy for TMJ was maintained in these subjects. On top of that, oral function

145 training was implemented as well. 5) Tongue and lip mobility and coordination training, and

146 instructions on food intake were included. 6) In cases where a fibular osteoseptocutaneous flap

147 was performed, the big toe and ankle joint were stretched in this phase to increase joint ROM and

148 soft tissue flexibility. The training programs were evaluated and adjusted as needed during every

149 visit. Each treatment session lasted for an average of $50 \mathrm{~min}$. Participants were also instructed to

150 perform individual home-programs on an hourly basis when awake at home. Compliance to home-

151 programs was checked having the patients keep diaries regarding their home endeavors. 
152 Late phase: The late phase started more than 3 months post-operation. The goal in this phase was

153 to recover the residual functions as much as possible. The interventions included were: 1) Pain and

154 scar management with intensity up to patient's tolerance and, 2) shoulder PRE programs were

155 implemented as in the previous phase, i.e. 10 repetitions each session 3) If microstomia was caused

156 by the intra-oral scar contracture after RT, a microstomia splint was prescribed and intra-oral scar

157 massage was applied. 3) Treatments to improve oral, shoulder joint and physical functioning were

158 performed and progressed according to individual performance. The participants attended the

159 rehabilitation center once a week. Each treatment session lasted for 1 hour during this phase. In

160 addition to a weekly visit to the rehabilitation center, patients were asked to perform their

161 individual home programs with hourly exercise of the TMJ and shoulder, and were also

162 encouraged to perform physical exercise (i.e. scar massage, mouth opening exercise, shoulder-

163 neck ROM and PRE, et al.) at least 3 to 5 times a week.

164 All the intervention program is based on a variety of clinical trials compiled in the review article

165 by Guru (2012)(Guru et al. 2012). 
166 All the treatments were provided by 3 certified therapists with an average of more than 10 years

167 of clinical experience.

168 Baseline data included demographic information and outcome variables taken during the 1st visit

169 after operation. Data at 1,3, and 6 months after the operation were also included. Furthermore,

170 return-to-work status of all subjects employed at baseline were followed at 12-month post

171 operation through telephone interview to confirm if they are back to work.

\section{Outcome measurements}

173 Demographic data including gender, age, marital status, education level, disease staging, oncology

174 and reconstructive treatment were collected after informed consent was given. Outcome

175 measurements included shoulder outcomes, oral health, health-related QoL and physical functions.

176 Shoulder outcomes were evaluated according to shoulder joint ROM and muscle strength (MMT),

177 the visual analog scale (VAS) for the assessment of shoulder pain, and the Disabilities of the Arm,

178 Shoulder and Hand (DASH) Outcome Measure for upper extremity function. Oral health was

179 evaluated using maximum mouth opening (MMO) and diet status, which was divided into 
180

181 182 183 184 185 MMT and ROM

186 The strength of the rotator cuff, pectoralis muscle, deltoid, trapezius, serratus anterior, rhomboid 187 188 189 190 191 contraindications in the prone position were indicated such as breathing difficulty. Interincisor nasogastric $(\mathrm{NG})$ tube feeding, liquid diet, soft diet or normal diet. Health-related QoL was evaluated using the European Organization for Research and Treatment of Cancer Quality of Life Questionnaire Core 30 (EORTC QLQ-C30) and Quality of Life Questionnaire Core Head and Neck 35 (QLQ-HN35), and using physical function evaluations. Six-minute walking distance (6MWD) and the timed up and go (TUG) tests were employed to evaluate physical function.

\author{
The strength of the rotator cuff, pectoralis muscle, deltoid, trapezius, serratus anterior, rhomboid
} and latissmus dorsi were evaluated according to the numerical grading system of Medical Research

Council (MRC) scale. A score of 4 is the acknowledged cut-off score that demonstrates the muscle's ability to hold testing position against gravity and moderate resistance.(Mark 2017) Shoulder joint ROM was evaluated in flexion, abduction, external rotation, and internal rotation with a two-arm goniometer under standard procedures. The evaluation was terminated when any

193 distance (IID) was collected in millimeters by a Willis gauge, in the case of healthy teeth. Maximal

194 mouth opening (MMO) was measured by measuring the difference between the distances between 
195 the nose tip to mandible during mouth opening and mouth closing.

196 DASH outcome measure

197 The DASH outcome measure is a self-report questionnaire and a clinical tool to measure physical

198 function and symptoms of the upper extremity, which studies have found useful for patients after

199 neck dissection.(Carr et al. 2009; Chan et al. 2015) The disability/symptom section contains 30

200 items scored from 1 to 5 indicating "no difficulty" to "unable" to perform the task. At least 27

201 items must be completed, scores are consequently transformed into a total scale of 1-100. Higher

202 scores indicate greater disability. A minimum clinically important difference (MCID) was used to

203 assess the smallest perceived important change.(Cranney et al. 2001) A change score exceeding

20415 points is the most accurate change score for discriminating between improved and unimproved

205 state.(Beaton et al. 2001)

\section{EORTC QLQ-C30 and QLQ-HN35}

207 The EORTC QLQ-C30 is a questionnaire developed to evaluate the general quality of life of cancer

patients. The QLQ-H\&N35 is one of the disease-specific module supplements for head and neck

cancer. The QLQ-H\&N35, in conjunction with the QLQ-C30, is considered a reliable and valid 
210 assessment of the quality of life among patients with head and neck cancer in various different

211 countries.(Bjordal et al. 2000; Chie et al. 2010; Scherman et al. 2000) The EORTC QLQ-C30

212 contains 30 questions and is divided into a global health scale, 5 functional (physical, role,

213 cognitive, emotional, and social) scales, and 9 symptom (fatigue, pain, nausea/vomiting, dyspnea,

214 insomnia, appetite loss, constipation, diarrhea, and financial difficulties) scales. The EORTC

215 QLQ-H\&N35 contains 35 questions and is divided into 6 symptom scales (pain, swallowing,

216 senses [taste/smell], speech, social eating, and social contact), and 7 single items (impaired

217 sexuality, teeth problems, mouth opening, dry mouth, sticky saliva, coughing, and feeling ill).

218 Every scale is transformed into a score ranging from 0 to 100 . A higher score on the functional

219 scale or global health scale represents a higher level of functioning or quality of life. In contrast, a

220 higher score on the symptom scale or single item scale reflects a worse symptom or problem.

\section{Physical functions}

222 The 6-minute walking distance (6MWD) and the timed up and go (TUG) tests were employed to

223 evaluate physical capacity and lower extremity function. 6MWD is a tool used to evaluate

224 functional exercise capacity of cancer patients and has been suggested to be as valid and reliable 
225 in this context as it is in evaluating cardiopulmonary patients.(Schmidt et al. 2013) The test was

226 performed in 6 minutes, and the patients were asked to walk to the end and back on a $20 \mathrm{~m}$ walkway

227 as fast as they can, without overexertion. The total distance was recorded in millimeters. The TUG

228 test is a commonly used tool that is evidently based to predict functional mobility and stability in

229 less healthy, lower-functioning adults(Schoene et al. 2013). It measures the time in seconds to

230 stand up from a sitting position on a chair, walk 3 meters, turn, walk back, and to sit back down

231 on the chair.

232 All the evaluations were conducted by a different group of 2 certified therapists blinded to the

233 study, with an average 12.5 years of clinical experience.

\section{Statistical analysis}

235 SPSS 20.0 was used in the data analysis with a maximum significance level set at 0.05 .

236 Independent t-tests were used for the analysis of continuous variables. For the categorical data,

237 chi-squared tests or Fisher's exact tests were used to analyze differences in the independent

238 variables of gender, marital status, educational level, breadwinner, vocation, TNM stage, neck 
239 dissection, radiation therapy, diet and donor site, while independent t-tests were applied to test for

240 differences in the dependent variables of age, 6MWD and TUG. The Generalized Estimating

241 Equations (GEE) procedure was conducted to analyze repeated measures outcome variables over

242 time. We used GEE model which assumed unstructured working correlation matrix. GEE has the

243 benefit of a robust estimator, and it can overcome the limitation of missing data and adjust for

244 correlations between observations as well. Separate models were run for each outcome variable.

245 Bilateral shoulders were evaluated separately when bilateral neck dissections had been performed.

246 The data were excluded if the participants had shoulder problems before the operation. Pearson

247 correlation coefficient was used to measure the degree of association between outcome variables.

248 Kaplan-Meier Estimates were used for the survival analysis to predict the rate of return-to-work.

249 The log rank test was conducted to compare differences in the rate of return-to-work between the

250 early stage and advanced stage groups.

251

252 RESULTS

253 Study population 
254 A total of 65 participants (60 male and 5 female, mean age 51.6 years) who underwent 80 neck

255 dissections (15 subjects received bilateral neck dissections), were analyzed in this study after

256 reconstructive microsurgery. Thirteen eligible subjects declined to enroll. The drop-out rate was

$25734 \%$. The reason was decondition and fatigue caused by RT that decreased their willingness to

258 participate in the intervention program. The CONSORT flow diagram is shown in Figure 3 . The

259 demographic data are summarized in Table 1. A supplementary Table is provided to present the

260 demographic comparison between the drop-out and the analytic groups. To explore differences in

261 the outcomes between the early stage and the advanced stage group, we compared them with

262 respect to all variables of interest (using group model). Apart from the disease-related variables,

263 there were no significant differences in the demographic data of the early staged group and the

264 advanced group.

265 Shoulder outcomes

266 All participants had neck dissections, and none had a prior history of shoulder pain. With respect

267 to shoulder ROM of the affected shoulder, only abduction showed a significant difference between

2686 months and baseline or compared with the unaffected side during 6 months of the study $(p<.001)$ 
269 (Table 2 and 3). MMT of the middle trapezius, lower trapezius and rhomboid muscles were not

270 performed at the baseline because patients were unable to comfortably maintain a prone posture.

271 The muscle strength of the infraspinatus, subscapularis, teres muscles, pectoralis muscles and

272 latissmus dorsi demonstrated normal strength at the baseline and exhibited no significant

273 differences in the subsequent tests. Apart from the upper trapezius and levator scapular which

274 gained stability of normal strength $(4.9 \pm 0.3) 1$-month post operation (Table 2$)$, the anterior and

275 middle deltoid, trapezius, serratus anterior, rhomboid all showed significant differences in strength

276 between the 6-month assessment compared to baseline, 1 month and 3 months, individually

$277(p<.001)$ (Table 2$)$. At 1-month evaluation, only middle and lower trapezius scored less than 4 on

278 the MMT scale. Other muscles attained sufficient strength to overcome some resistance and

279 gravity. Comparison of the ratio of the shoulder outcomes of the neck dissection side and the sound

280 side indicates that the shoulder ROM and muscle strength reached almost equivalent level to the

281 sound side except in the middle and lower trapezius at 6 months of the study (Table 3).

282 The average shoulder pain score on the VAS was $1.81 \pm 2.28$ at the baseline, and $1.09 \pm 1.89$ at 6

283 months. VAS scores showed no significant difference between 6 month and baseline. However, 
284 the pain scale measured in the self-reported quality-of-life questionnaire EORTC QLQ-C30

285 showed a significantly higher score at the baseline $(44.9 \pm 26.0)(p<.001)$ compared with

286 subsequent evaluations (Table 4). The mean DASH score at the baseline was $34.4 \pm 24.0$ and

287 significantly dropped to $17.4 \pm 16.2$ at 1 month $(p<.001)$, which was considered a minimum

288 clinically important difference (MCID).

289 Oral health outcomes

290 At the baseline, a nasogastric (NG) tube was placed for all participants. 1 month after the operation,

$29118 \%$ persisted with NG tube feeding, $14 \%$ returned to normal diet, $28 \%$ and $40 \%$ started to get

292 nutrition with a liquid and a soft diet, respectively. At 6 months, all NG tubes had been removed,

293 and $53 \%$ returned to normal diet. $16 \%$ and $31 \%$ participants were able to orally intake a liquid and

294 a soft diet.

295 IID and MMO had high positive correlation ( $\mathrm{r}=.883)$. The mean IID was $22.5 \pm 9.2$ millimeters and

296 significantly progressed to $31.8 \pm 11.8$ millimeters $(p<.001)$ in the overall model. The mean MMO

297 was $22.6 \pm 2.1$ millimeters (baseline) and $31.8 \pm 10.1$ millimeters (6 months), which was also a 
298 statistically significant difference $(p<.001)$. In the group model, IID and MMO for both early stage

299 and advanced stage groups significantly increased at 6 months compared to baseline, 1, and 3

300 months, individually as well. In the early stage group, IID increased from $21.8 \pm 7.9$ (baseline) to

$30134.0 \pm 13.7$ (6 months) $(p<.001)$, and it increased from $23.1 \pm 10.1$ (baseline) to $29.1 \pm 8.6(6$ months)

$302(p=.010)$ in the advanced stage group

303 Health related quality of life and physical functions

304 Table 4 illustrates the results of the EORTC QLQ-C30 scales. After 6 months of intensive physical

305 therapy, health-related quality of life was significantly different $(p<.05)$ from the baseline on the

306 global health scale and all functional scales, except cognitive function. The symptom scales of

307 fatigue, nausea/vomiting, pain, dyspnea and insomnia showed significant differences between the

308 baseline and 6-month scores or between 3-month and 6-month scores $(p<.05)$ for the overall and

309 group models. However, no significant difference was found on the scales of constipation over

310 time throughout the 6 months. While the scales of loss of appetite, diarrhea, and financial problems

311 showed significantly high scores $(p<.05)$ at baseline compared with 6-month scores in the early 
312 stage group, it maintained at similar level over time throughout the 6 months in the advanced stage

313 group.

314 Table 5 illustrates the results from the EORTC QLQ-H\&N35 scales. All other symptom scales

315 showed a significant difference $(p<.05)$ between the 6-month test scores and the baseline scores

316 in overall model and group model except on the scale on senses (tastes, smell) which showed no

317 significant difference over 6 months in the early stage group. Oral pain, swallowing, and speech

318 scores on the 3 -month test were significantly different $(p<.05)$ compared with those on the 6-

319 month test in the advanced group. The single item scales of opening mouth, dry mouth, sticky

320 saliva and coughing showed significant differences between the baseline and 6-month scores, and

321 between 3-month and 6-month scores $(p<.05)$ except for the score on teeth and sexuality, which

322 maintained at the same level over the 6 months in the early stage group and the advanced group.

323 At 3-months and 6-months, 6MWD was 339.0 $\pm 54.4 \mathrm{~m}$ and $381.2 \pm 69.9 \mathrm{~m}$, respectively $(p<.001)$.

324 TUG was 10.6 \pm 2.4 seconds at 3 months and $8.4 \pm 1.5$ seconds at 6 -months $(p<.001)$. 6MWD on

325 the 3-month and 6-month tests, respectively, was $355.5 \pm 55.9 \mathrm{~m}$ and $396.5 \pm 73.5 \mathrm{~m}(p=.029)$ in the 
326 early stage group, and $321.6 \pm 48.2 \mathrm{~m}$ and $363.1 \pm 64.0 \mathrm{~m}$ in the advanced stage group ( $p=.003)$. No

327 significant difference was found between groups at 3 or 6 months on either measure.

328 Our analysis found a predicted return-to-work rate of $34.7 \%$ at 3 months, $63.0 \%$ at the 6 months

329 and $80 \%$ at 1 year after surgery, respectively. The log rank test showed the time of return-to-work

330 was significantly different between the early stage group and the advanced stage $(p=.032)$. In the

331 early stage group, it predicted that about $80 \%$ would return to work 1 year after the operation, but

332 around 50\% would return to work in the advanced stage group (Fig 4). Further analysis showed

$33371.4 \%$ return-to-work rate in the retired or unemployed, $86.7 \%$ in the self-employed, $80 \%$ in the

334 professional, $33.3 \%$ in the administration, $81.8 \%$ in the service and $87.5 \%$ in the semi-skilled or

335 skilled according to vocational type.

\section{DISCUSSION}

337 In this single-arm pilot study we investigated early physical therapy interventions designed to

338 improve active shoulder abduction and muscle strength surrounding the scapula. Shoulder

339 functions including joint ROM, MMT, pain and DASH in the initial 6- month post-operation were 
340 measured. In the early phase, the average shoulder ROM was limited to less than one-third the

341 normal range, after which shoulder abduction had significantly improved at 6-months post-

342 surgery. In the model analyzed by the GEE procedure, the strength of the muscle group responsible

343 for scapular stabilization, consisting of the trapezius, serratus anterior, and rhomboid, significantly

344 improved during the 6 months. Furthermore, the deltoid and supraspinatus muscle also showed

345 improvements in this study. Average shoulder pain measured by VAS did not exceed 2 at the

346 baseline and the following 6 months. The DASH outcome measure reached MCID at the 1-month

347 evaluation, and maintained up to 6 months after the operation.

348 Ewing and Martin found shoulder problems after neck dissection with a clinical picture that

349 included drooping of the shoulder, limited forward flexion, lateral abduction and rotation of the

350 shoulder and reduced EMG activity.(Ewing \& Martin 1952) EMG studies also showed that

351 trapezius muscle activity decreased after neck dissection.(Lima et al. 2011; McGarvey et al. 2013a;

352 Parikh et al. 2012) In our study, shoulder ROM and upper trapezius strength almost fully recovered

353 during the early stage of physical therapy intervention, and scapular muscle strength showed

354 continuous progress throughout the 6-month study period after the operation. PRE training has 
355 been found to improve shoulder function compared with standard intervention following neck

356 dissection in randomized controlled trials.(McNeely et al. 2004; McNeely et al. 2008) The timing

357 of the physical therapy intervention in these previous studies was categorized into early and late

358 stages. Early intervention seems to have some positive impact on this diagnostic group of patients

359 and its change persisted for the entire 6 months of observation.

360 In previous studies, the target muscles included the upper trapezius ignoring the lower trapezius.

361 An interesting finding of this study is that the upper trapezius gained normal level of strength soon

362 after 1 month of intervention, but the middle and lower trapezius did not show a return to normal

363 levels until after 6 months of intervention. In our model, the VAS and DASH scores showed mild

364 disturbance at 6 months after surgery. This may be related to the impaired middle and lower

365 trapezius, and needs further study in the future. In the reviewed articles, support of the beneficial

366 effect of physical therapy for ANSD following neck dissection lacks convincing evidence.(Bradley

367 et al. 2011; Carvalho et al. 2012; McGarvey et al. 2011) In recent studies, PRE was introduced for

368 the target muscles acting as scapular stabilizers (the upper trapezius, middle trapezius, rhomboid

369 major, and serratus anterior muscle) rather than for the muscles surrounding the glenohumeral 
370 joint.(Lima et al. 2011; McGarvey et al. 2013a; McGarvey et al. 2013b) Improvements were

371 observed in scapular muscles receiving PRE within 6 months after the operation. We suggest that

372 lower trapezius muscle strengthening should be considered in the ANSD population.

373 TMJ ROM was measured by IID and MMO in this study. Our participants started to exercise their

374 TMJ once the wound was stable, at an average of 8.3-days post-operation. Briefly speaking, our

375 strategy was to promote early mobilization of the TMJ. The results showed a near $10 \mathrm{~mm}$ increase

376 in TMJ ROM in 6 months. In the group model, the potential was more obvious in the early stage

377 group. Early intervention to exercise the TMJ, may improve mouth opening. In the advanced stage

378 group, the maximum mouth opening reached its highest at 3 months. This phenomenon may be

379 related to RT. In our series, a higher rate of patients needed to receive RT among the advanced

380 stage patients, which is consistent with other studies.(Wetzels et al. 2014) We measured MMO by

381 the method described by McCord J.(McCord 2000) This method can overcome the issue of missing

382 teeth, and was highly correlated with the distance between incisors measured by a Willis gauge

383 after our analysis. 
384 We tested 6MWD to evaluate the prognosis of functional capacity and lower extremity function.

385 Bellet et al. systematically reviewed fifteen articles and concluded that 6MWD has strong evidence

386 in support of its use to evaluate clinical change following cardiac rehabilitation.(Bellet et al. 2012)

387 6MWD is significantly correlated with peak aerobic capacity (VO2peak). It is considered the gold

388 standard outcome and is easily accessible in clinical practice.(Schmidt et al. 2013) Our results

389 showed that 6MWD significantly improved between the 3- and 6-month evaluations in both the

390 overall and group model. In Liu's study, they performed the 6MWD test before and after 3 months

391 of home-based exercise to evaluate lower extremity function after fibula osteocutaneous flap

392 reconstruction for mandibular defects in oral cancer patients.(Liu et al. 2013) Their results showed

393 no significant difference in the walking distance. The exercise intervention was almost 1 year after

394 surgery. In our series, the donor sites were harvested mostly from the lower extremity. The total

395 walking distance and timed up and go (TUG) scores increased significantly in the first 3 months

396 in both the overall and group model. Improved functional capacity and mobility may have been a

397 factor contributing to early return-to-work. Return to work in many cancer survivors is a realistic

398 outcome. Further study of the effect of rehabilitation on functional restoration and quality of life 
399 for oral cancer survivors is needed. In this study, our results suggested that early intervention and

400 good compliance might help $80 \%$ of oral cancer survivors return to work within 1 year post-

401 operation. We found a significant difference in the group model indicating that the cohort of early

402 stage survivors returned faster and had a higher rate of return than the cohort of advanced stage

403 survivors. In addition, return-to-work rate differs in different vocational types, with a higher rate

404 of return in the skilled or semi-skilled and self-employed. In this study, samples are small in

405 number in varied vocational types, further statistical analysis would convey little information.

406 However, this would be an issue worth further investigation.

407 In this 6-month goal-oriented rehabilitation program for the population of oral cancer survivors,

408 the health-related QoL were observed to improve. In the domains measured by the EORTC QLQ-

409 C30 scales and EORTC QLQ-H\&N35 scales, the global health and other functional scales, except

410 for cognitive function, improved significantly in the first month. Global health and physical

411 function continued to improve throughout the 6 months. In our comparison of the early stage group

412 and the advanced stage group, we found that global health and physical function deteriorated at

413 the 3-month evaluation in the advanced stage survivors. In some of the symptom and single item 
414 scales the same trend was observed, with the participant self-ratings being the worst at 3 months.

415 These items included oral pain, swallowing, senses, speech, sticky saliva, feeling ill, and global

416 health. As these are common side effects of radiation, they received low self-ratings at post-

417 operative month 3 may be explained by the onset of RT. This finding is consistent with other

418 studies.(Ch'ng et al. 2014; Tribius et al. 2015) We discovered that the progression of some self-

419 rated scales might be different in the group model. For example, global health reached a relatively

420 stable score by the third month in the early stage group, whereas the score decreased at the 3-

421 month evaluation compared to baseline and recovered to the level measured at post-operative

422 month 1 in the advanced stage group by 6-month evaluation. Self-rated health is a cognitive

423 process, which is affected by internal and external factors.(Huisman \& Deeg 2010; Jylha 2009)

424 We evaluated the outcomes of an early- and integrated-intervention program focused primarily on

425 oral cavity function and secondarily on issues that result from the oncological and reconstructive

426 surgery, and found significant improvement on several items within the 6 month study period.

427 The limitation of this study is the rather high loss rate up to 34\%. In addition, follow-up lasted for

428 only 6 months after surgery and the limited number of subjects recruited in this study. The shoulder 
429 pain and DASH scores still indicated mild impairment at the 6-month evaluation. As a single-arm

430 pilot study, tracking outcomes of subjects who had received oral cancer reconstruction surgery

431 with early intervention rehabilitation program is our main objective. The results herein convey a

432 possible application of early intervention to this diagnostic group of patients. The effect of early

433 PRE intervention to the target muscles would be a worthwhile focus of future studies in this

434 population. In addition, substantial outcomes were evaluated on limited number of subjects

435 recruited in this study which might lead to a false -positive analytic results. An inclusion of a

436 control group may warrant a better estimate of the effect of an early intervention to this group of

437 patients as well.

438 CONCLUSION

439 Our results showed that shoulder joint range of motion and muscle strength progressively

440 improved during the 6 months of observation, as did oral function and global health. Though

441 subjects in this study underwent a comprehensive intervention program lasting only 6 months, all

442 showed continued improvements in oral, upper extremity and lower extremity functions, as well

443 as recovery of social roles (return to work). We suggest an early and integrated intervention, and 
444 a follow-up of at least 6 months following reconstructive surgery for future studies and clinical

445 trials for oral cancer survivors; however, with discretion toward patients receiving radiation

446 therapy.

\section{Acknowledgments}

448 The authors sincerely thank the clinical staffs and participants in their contribution with regards to

449 data collection. We also thank the Center for Big Data Analytics and Statistics for statistical

450 support (Project No. CLRPG3D0044).

451

\section{REFERENCES}

453 Barrios R, Bravo M, Gil-Montoya JA, Martinez-Lara I, Garcia-Medina B, and Tsakos G. 2015. to control group. Health Qual Life Outcomes 13:9. 10.1186/s12955-014-0201-5

456 Beaton DE, Bombardier C, Katz JN, Wright JG, Wells G, Boers M, Strand V, and Shea B. 2001. 
Important Difference. J Rheumatol 28:400-405.

460

461

462

463

464

465

466

467

468

469

470

471

472

473

rehabilitation: validity, reliability and responsiveness--a systematic review.

Physiotherapy 98:277-286. 10.1016/j.physio.2011.11.003

Bjordal K, de Graeff A, Fayers PM, Hammerlid E, van Pottelsberghe C, Curran D, Ahlner-

Elmqvist M, Maher EJ, Meyza JW, Bredart A, Soderholm AL, Arraras JJ, Feine JS,

Abendstein H, Morton RP, Pignon T, Huguenin P, Bottomly A, and Kaasa S. 2000. A 12

country field study of the EORTC QLQ-C30 (version 3.0) and the head and neck cancer

specific module (EORTC QLQ-H\&N35) in head and neck patients. EORTC Quality of

Life Group. Eur J Cancer 36:1796-1807.

Bradley PJ, Ferlito A, Silver CE, Takes RP, Woolgar JA, Strojan P, Suarez C, Coskun H, Zbaren P, and Rinaldo A. 2011. Neck treatment and shoulder morbidity: still a challenge. Head Neck 33:1060-1067. 10.1002/hed.21495

Cappiello J, Piazza C, Giudice M, De Maria G, and Nicolai P. 2005. Shoulder disability after different selective neck dissections (levels II-IV versus levels II-V): A comparative 
study. Laryngoscope 115:259-263. 10.1097/01.mlg.0000154729.31281.da

475 Carr SD, Bowyer D, and Cox G. 2009. Upper limb dysfunction following selective neck

476 dissection: a retrospective questionnaire study. Head Neck 31:789-792.

477 $10.1002 /$ hed.21018

478

479

480

481

482

483

484

485

486

487 patients treated for head and neck cancer. Cochrane Database Syst Rev 4:CD008693. 10.1002/14651858.CD008693.pub2

Ch'ng S, Oates J, Gao K, Foo K, Davies S, Brunner M, and Clark JR. 2014. Prospective quality of life assessment between treatment groups for oral cavity squamous cell carcinoma. Head Neck 36:834-840. 10.1002/hed.23387

Chan JY, Wong ST, Chan RC, and Wei WI. 2015. Shoulder Dysfunction after Selective Neck Dissection in Recurrent Nasopharyngeal Carcinoma. Otolaryngol Head Neck Surg $153: 379-384.10 .1177 / 0194599815590589$

Chie WC, Tsai CJ, Chiang C, and Lee YC. 2010. Quality of life of patients with oesophageal cancer in Taiwan: validation and application of the Taiwan Chinese (Mandarin) version 
of the EORTC QLQ-OES18: a brief communication. Qual Life Res 19:1127-1131.

490

$10.1007 / \mathrm{s} 11136-010-9675-8$

491 Cranney A, Welch V, Wells G, Adachi J, Shea B, Simon L, and Tugwell P. 2001. Discrimination

492 of changes in osteoporosis outcomes. J Rheumatol 28:413-421.

493

Dijkstra PU, van Wilgen PC, Buijs RP, Brendeke W, de Goede CJ, Kerst A, Koolstra M,

494

Marinus J, Schoppink EM, Stuiver MM, van de Velde CF, and Roodenburg JL. 2001.

495 Incidence of shoulder pain after neck dissection: a clinical explorative study for risk

496 factors. Head Neck 23:947-953.

497 Erisen L, Basel B, Irdesel J, Zarifoglu M, Coskun H, Basut O, Tezel I, Hizalan I, and Onart S. 2004. Shoulder function after accessory nerve-sparing neck dissections. Head Neck

499 26:967-971. 10.1002/hed.20095 based on the postoperative evaluation of 100 patients. Cancer 5:873-883.

502 Guru K, Manoor UK, and Supe SS. 2012. A comprehensive review of head and neck cancer rehabilitation: physical therapy perspectives. Indian J Palliat Care 18:87-97. 
505 Huisman M, and Deeg DJ. 2010. A commentary on Marja Jylha's "What is self-rated health and why does it predict mortality? Towards a unified conceptual model"(69:3, 2009, 307316). Soc Sci Med 70:652-654; discussion 655-657. 10.1016/j.socscimed.2009.11.003

508

509

510

511

512

513

514

515

516

517

Jylha M. 2009. What is self-rated health and why does it predict mortality? Towards a unified conceptual model. Soc Sci Med 69:307-316. 10.1016/j.socscimed.2009.05.013

Krishna Rao SV, Mejia G, Roberts-Thomson K, and Logan R. 2013. Epidemiology of oral cancer in Asia in the past decade--an update (2000-2012). Asian Pac J Cancer Prev 14:5567-5577.

Lima LP, Amar A, and Lehn CN. 2011. Spinal accessory nerve neuropathy following neck dissection. Braz J Otorhinolaryngol 77:259-262.

Liu TY, Huang YC, Leong CP, Tseng CY, and Kuo YR. 2013. Home-based exercise on functional outcome of the donor lower extremity in oral cancer patients after fibula flap harvest. Biomed J 36:90-95. 10.4103/2319-4170.110370 
520 Marur S, and Forastiere AA. 2016. Head and Neck Squamous Cell Carcinoma: Update on

521 Epidemiology, Diagnosis, and Treatment. Mayo Clin Proc 91:386-396.

522 10.1016/j.mayocp.2015.12.017

523 McCord J. 2000. Registration: Stage II-intermaxillary relations. British dental journal 188.

524 McGarvey AC, Chiarelli PE, Osmotherly PG, and Hoffman GR. 2011. Physiotherapy for 525 accessory nerve shoulder dysfunction following neck dissection surgery: a literature 526 review. Head Neck 33:274-280. 10.1002/hed.21366

527 McGarvey AC, Osmotherly PG, Hoffman GR, and Chiarelli PE. 2013a. Impact of neck dissection on scapular muscle function: a case-controlled electromyographic study. Arch Phys Med Rehabil 94:113-119. 10.1016/j.apmr.2012.07.017

530 McGarvey AC, Osmotherly PG, Hoffman GR, and Chiarelli PE. 2013b. Scapular muscle 531 exercises following neck dissection surgery for head and neck cancer: a comparative electromyographic study. Phys Ther 93:786-797. 10.2522/ptj.20120385

533 McNeely ML, Parliament M, Courneya KS, Seikaly H, Jha N, Scrimger R, and Hanson J. 2004. 
534

535

536

537

538

539

540

541 McNeely ML, Parliament MB, Seikaly H, Jha N, Magee DJ, Haykowsky MJ, and Courneya KS.

542

543

544

545

546

A pilot study of a randomized controlled trial to evaluate the effects of progressive

resistance exercise training on shoulder dysfunction caused by spinal accessory

neurapraxia/neurectomy in head and neck cancer survivors. Head Neck 26:518-530.

10.1002/hed.20010

McNeely ML, Parliament MB, Seikaly H, Jha N, Magee DJ, Haykowsky MJ, and Courneya KS. 2008. Effect of exercise on upper extremity pain and dysfunction in head and neck cancer survivors: a randomized controlled trial. Cancer 113:214-222. 10.1002/cncr.23536 2015. Sustainability of outcomes after a randomized crossover trial of resistance exercise for shoulder dysfunction in survivors of head and neck cancer. Physiother Can 67:85-93. $10.3138 /$ ptc. $2014-130$

Parikh S, Tedman BM, Scott B, Lowe D, and Rogers SN. 2012. A double blind randomised trial of IIb or not IIb neck dissections on electromyography, clinical examination, and questionnaire-based outcomes: a feasibility study. Br J Oral Maxillofac Surg 50:394-403. 
549 Sankaranarayanan R, Ramadas K, Amarasinghe H, Subramanian S, and Johnson N. 2015. Oral

550 Cancer: Prevention, Early Detection, and Treatment. In: Gelband H, Jha P,

551 Sankaranarayanan R, and Horton S, eds. Cancer: Disease Control Priorities, Third

552 Edition (Volume 3). Washington (DC).

553 Scherman A, Simonton S, and Adams D. 2000. Assessing quality of life in patients with head

$554 \quad$ and neck cancer. Arch Otolaryngol Head Neck Surg 126:459-467.

555 Schliephake H, and Jamil MU. 2002. Prospective evaluation of quality of life after oncologic

556

surgery for oral cancer. Int J Oral Maxillofac Surg 31:427-433. 10.1054/ijom.2001.0194

557 Schmidt K, Vogt L, Thiel C, Jager E, and Banzer W. 2013. Validity of the six-minute walk test

in cancer patients. Int J Sports Med 34:631-636. 10.1055/s-0032-1323746

559 Schoene D, Wu SM, Mikolaizak AS, Menant JC, Smith ST, Delbaere K, and Lord SR. 2013.

560 Discriminative ability and predictive validity of the timed up and go test in identifying

$561 \quad$ older people who fall: systematic review and meta-analysis. J Am Geriatr Soc 61:202-

$562 \quad$ 208. $10.1111 /$ jgs. 12106

563 Sheikh A, Shallwani H, and Ghaffar S. 2014. Postoperative shoulder function after different 

types of neck dissection in head and neck cancer. Ear Nose Throat J 93:E21-26.

565 Stuiver MM, van Wilgen CP, de Boer EM, de Goede CJT, Koolstra M, van Opzeeland A, complaints after neck dissection on shoulder disability and quality of life. Otolaryngology -- Head and Neck Surgery 139:32-39. 10.1016/j.otohns.2008.03.019 radiotherapy for patients with locally advanced head and neck cancer: Results of a prospective study. Strahlenther Onkol 191:501-510. 10.1007/s00066-015-0824-4

573

574

575

576

577 Venema P, Sterken MW, Vincent A, and Dijkstra PU. 2008. Impact of shoulder

S. 2015. Residual deficits in quality of life one year after intensity-modulated

Umeda M, Shigeta T, Takahashi H, Oguni A, Kataoka T, Minamikawa T, Shibuya Y, and Komori T. 2010. Shoulder mobility after spinal accessory nerve-sparing modified radical neck dissection in oral cancer patients. Oral Surgery, Oral Medicine, Oral Pathology, Oral Radiology, and Endodontology 109:820-824. DOI: 10.1016/j.tripleo.2009.11.027 van Wilgen CP, Dijkstra PU, van der Laan BFAM, Plukker JT, and Roodenburg JLN. 2003. Shoulder complaints after neck dissection; is the spinal accessory nerve involved? British 
580 Wetzels JW, Merkx MA, de Haan AF, Koole R, and Speksnijder CM. 2014. Maximum mouth opening and trismus in 143 patients treated for oral cancer: A 1-year prospective study.

583

584 FIGURE LEGENDS

585 Fig 1. Scapula control exercise. (A-C) Anti-scapular winging exercise: bilateral hands held

586 together and elevated to the top then placed behind the head, pulling the bilateral scapular closer.

587 (D) Wall press exercise. (E) Wall press with scapular elevation exercise. (F) Wall press with arm

588 clock exercise.

589

590 Fig 2. Progressive resistance exercise (PRE) training. (A) Shoulder diagonal flexion with thera-

591 band. (B) Shoulder horizontal abduction and scapulae retraction with thera-band. (C) Shoulder

592 flexion and abduction with free weights. 
594 Fig. 3 The CONSORT flow chart.

595

596 Fig 4. Curve of the percentage of return-to-work patients at post-operative month in the early and

597 advanced stage groups. 


\section{Figure 1}

Scapula control exercise.

(A-C) Anti-scapular winging exercise: bilateral hands held together and elevated to the top then placed behind the head, pulling the bilateral scapular closer. (D) Wall press exercise. (E) Wall press with scapular elevation exercise. (F) Wall press with arm clock exercise.

\section{$\mathbf{A}$}

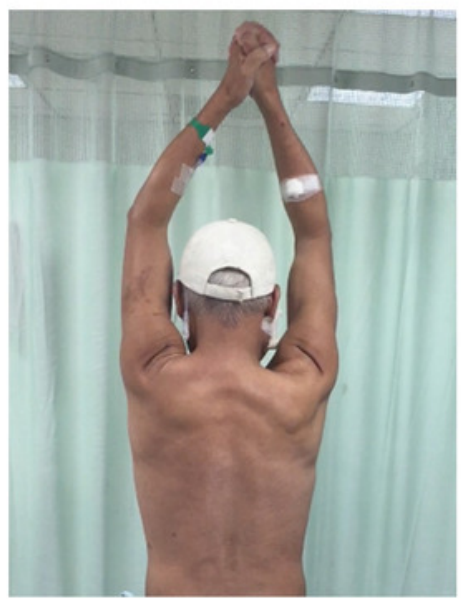

D

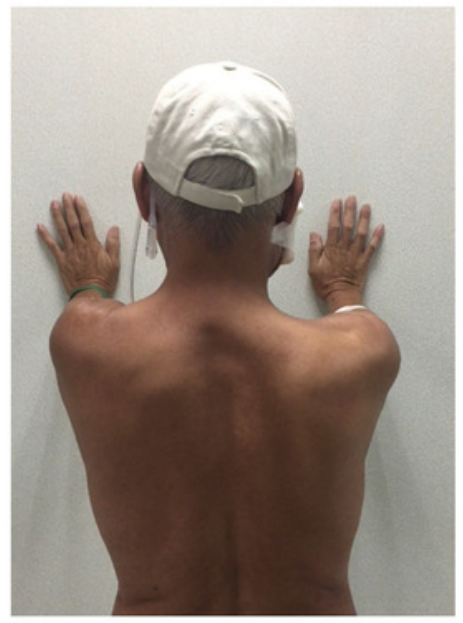

B

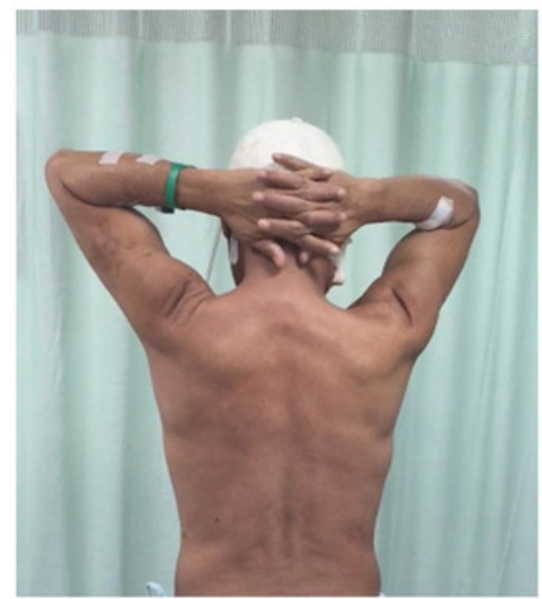

$\mathbf{E}$

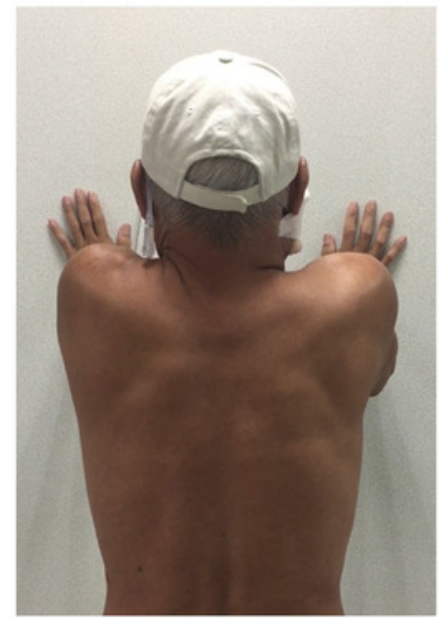

C

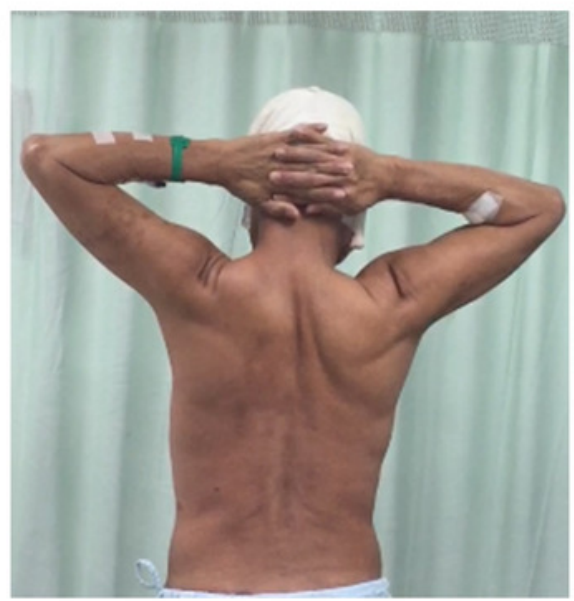

F

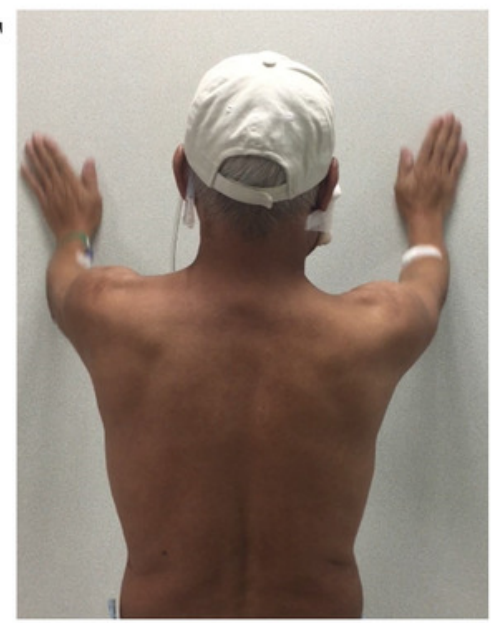




\section{Figure 2}

Progressive resistance exercise (PRE) training.

(A) Shoulder diagonal flexion with thera-band. (B) Shoulder horizontal abduction and scapulae retraction with thera-band. (C) Shoulder flexion and abduction with free weights.
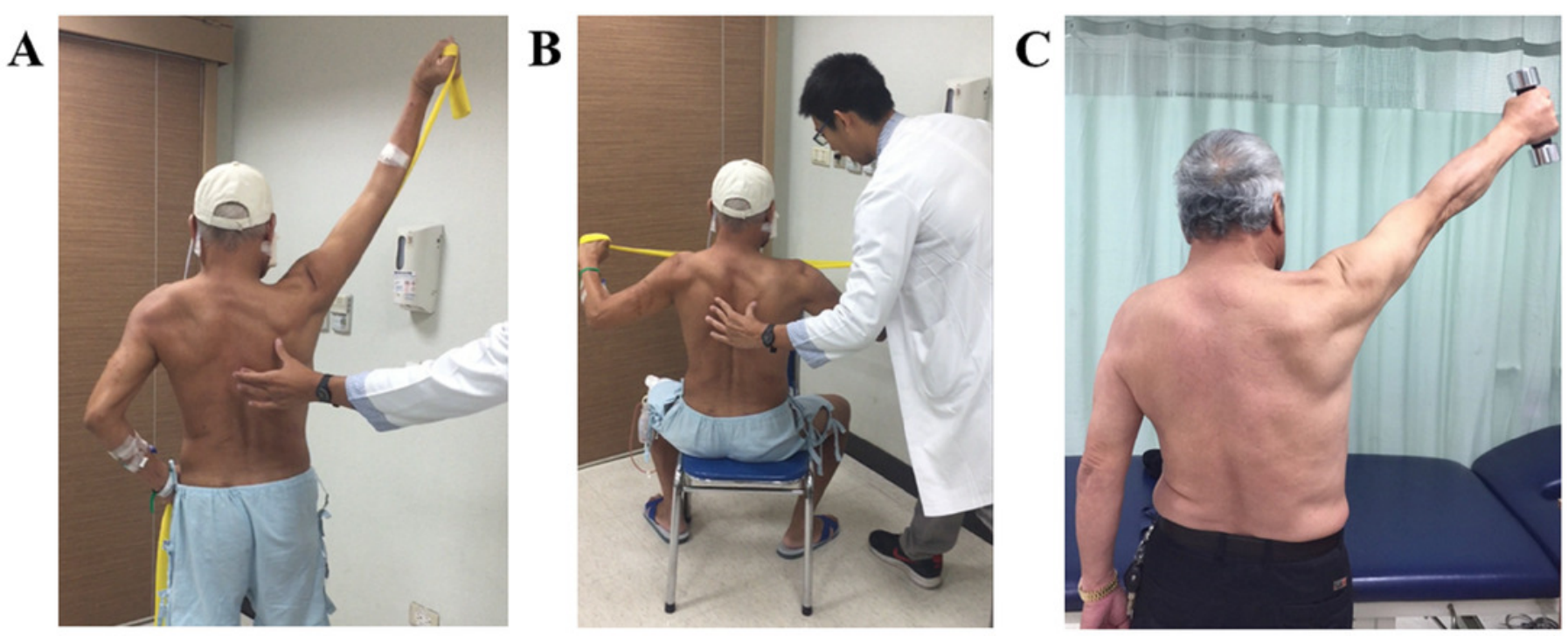
Figure 3

The CONSORT flow chart.

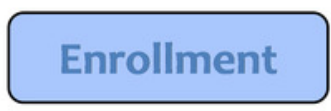

\section{Follow-Up}

Analysis
Assessed for eligibility $(n=317)$

Excluded $(n=219)$

- Not meeting inclusion criteria $(n=206)$

- Declined to participate $(n=13)$

Allocated to intervention $(n=98)$

- Received allocated intervention $(n=98)$

- Did not receive allocated intervention $(n=0)$

Discontinued study $(n=33)$

- Discomfort caused by RT $(n=30)$

- Refused to follow-up ( $n=3)$

Analysed $(n=65)$

- Excluded from analysis $(n=0)$ 
Figure 4

Curve of the percentage of return-to-work patients at post-operative month in the early and advanced stage groups.

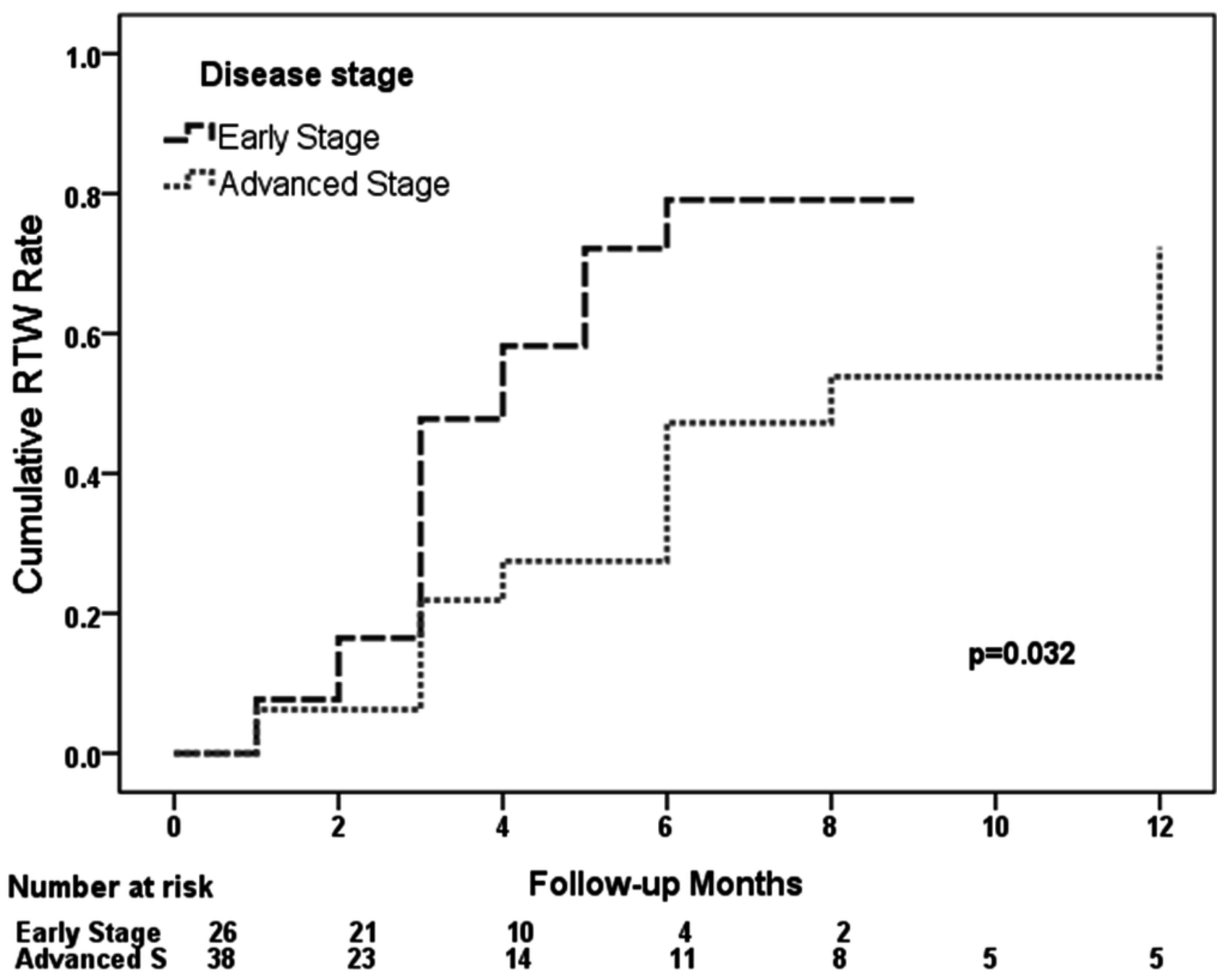




\section{Table 1 (on next page)}

Demographic and clinical characteristics of the study participants. 
Table 1. Demographic and clinical characteristics of the study participants.

\begin{tabular}{|c|c|c|c|c|}
\hline & & $\begin{array}{l}\text { Early stage } \\
\qquad(n=27)\end{array}$ & $\begin{array}{l}\text { Advanced stage } \\
\qquad(n=38)\end{array}$ & p-value \\
\hline Age & & $50.7 \pm 9.9$ & $51.8 \pm 10.6$ & .660 \\
\hline Gender & $\mathrm{F}$ & $3(11 \%)$ & $2(5 \%)$ & .642 \\
\hline & M & $24(89 \%)$ & $36(95 \%)$ & \\
\hline Education & $<9$ years & $10(39 \%)$ & $16(42 \%)$ & .878 \\
\hline & $9-12$ years & $13(46 \%)$ & $18(47 \%)$ & \\
\hline & $>12$ years & $4(15 \%)$ & $4(11 \%)$ & \\
\hline Marriage & Single & $3(11 \%)$ & $4(11 \%)$ & 1.000 \\
\hline & Married & $21(78 \%)$ & $30(79 \%)$ & \\
\hline & Other & $3(11 \%)$ & $4(11 \%)$ & \\
\hline Breadwinner & $\mathrm{N}$ & $10(37 \%)$ & $10(27 \%)$ & .394 \\
\hline & $\mathrm{Y}$ & $17(63 \%)$ & $28(73 \%)$ & \\
\hline Vocation & Retired/unemployed & $1(4 \%)$ & $7(18 \%)$ & .253 \\
\hline & Self-employed & $7(26 \%)$ & $8(21 \%)$ & \\
\hline & Professional & $3(11 \%)$ & $2(5 \%)$ & \\
\hline & Administration & $2(7 \%)$ & $1(3 \%)$ & \\
\hline & Service & $6(22 \%)$ & $4(11 \%)$ & \\
\hline & Semi-skilled/skilled & $8(30 \%)$ & $16(42 \%)$ & \\
\hline ND & Right & $10(37 \%)$ & $15(40 \%)$ & .002 \\
\hline & Left & $16(59 \%)$ & $9(24 \%)$ & \\
\hline & Bilateral & $1(4 \%)$ & $14(37 \%)$ & \\
\hline Area of tumor & Buccal & $11(41 \%)$ & $9(24 \%)$ & .714 \\
\hline & Tongue & $6(22 \%)$ & $11(29 \%)$ & \\
\hline & Mouth floor & $2(7 \%)$ & $6(16 \%)$ & \\
\hline & Gum & $4(15 \%)$ & $4(11 \%)$ & \\
\hline & Pharyngeal wall & $0(0 \%)$ & $2(5 \%)$ & \\
\hline & Lip & $1(4 \%)$ & $2(5 \%)$ & \\
\hline & Retromolar tumor & $2(7 \%)$ & $2(5 \%)$ & \\
\hline & Gingival & $0(0 \%)$ & $1(3 \%)$ & \\
\hline & Hard palate & $0(0 \%)$ & $1(3 \%)$ & \\
\hline
\end{tabular}




\begin{tabular}{|ll|c|c|c|} 
& Soft palate & $1(4 \%)$ & $0(0 \%)$ & \\
T stage & 1 & $8(30 \%)$ & $0(0 \%)$ & $<.001$ \\
& 2 & $19(70 \%)$ & $11(29 \%)$ & \\
& 3 & $0(0 \%)$ & $7(18 \%)$ & \\
N stage & 4 & $0(0 \%)$ & $20(53 \%)$ & \\
& 1 & $27(100 \%)$ & $10(26 \%)$ & $<.001$ \\
& 2 & $0(0 \%)$ & $8(21 \%)$ & \\
& 3 & $0(0 \%)$ & $19(50 \%)$ & \\
M stage & 0 & $0(0 \%)$ & $1(3 \%)$ & \\
Radiation & No & $27(100 \%)$ & $38(100 \%)$ & \\
& Yes & $20(74 \%)$ & $8(22 \%)$ & $<.001$ \\
Donor site & Anterolateral thigh & $7(26 \%)$ & $8(21 \%)$ & .089 \\
& Fibular & $1(4 \%)$ & $9(24 \%)$ & \\
& Other & $19(70 \%)$ & $21(55 \%)$ & \\
\hline
\end{tabular}




\section{Table 2 (on next page)}

Progression of ROM of shoulder joint and of MMT of scapular stabilizers. 
1 Table 2. Progression of ROM of shoulder joint and of MMT of scapular stabilizers.

\begin{tabular}{|c|c|c|c|c|c|c|c|c|c|}
\hline \multirow[b]{2}{*}{$\square$} & \multicolumn{2}{|c|}{ Baseline } & \multicolumn{2}{|c|}{1 month } & \multicolumn{2}{|c|}{3 months } & \multicolumn{2}{|c|}{6 months } & \multirow{2}{*}{$\begin{array}{l}p \text {-value } \\
\text { for trend }\end{array}$} \\
\hline & Mean & SD & Mean & SD & Mean & SD & Mean & SD & \\
\hline $\mathrm{ROM}\left(^{\circ}\right)$ & & & & & & & & & \\
\hline Flexion & 152.1 & 20.7 & 151.3 & 22.1 & 155.3 & 21.3 & 158.9 & 14.2 & .058 \\
\hline Abduction & 146.3 & 29.1 & 154.8 & 24.8 & 161.4 & 14.4 & 165.0 & 16.5 & $<.001$ \\
\hline IR & 74.5 & 10.3 & 77.1 & 9.0 & 72.0 & 8.7 & 70.8 & 11.3 & .108 \\
\hline ER & 79.7 & 14.8 & 82.3 & 10.2 & 81.3 & 10.0 & 82.2 & 11.2 & .337 \\
\hline MMT & & & & & & & & & \\
\hline MT & & & 4.2 & 0.9 & 4.4 & 0.7 & 4.8 & 0.4 & $<.001$ \\
\hline MLT & & & 2.7 & 1.0 & 2.8 & 1.1 & 3.4 & 1.3 & .001 \\
\hline RMM & & & 4.4 & 0.8 & 4.7 & 0.5 & 4.9 & 0.2 & $<.001$ \\
\hline SA & 4.2 & 0.9 & 4.5 & 0.6 & 4.6 & 0.7 & 4.9 & 0.4 & $<.001$ \\
\hline LUT & 4.6 & 0.8 & 4.9 & 0.3 & 4.9 & 0.3 & 5.0 & 0.2 & $<.001$ \\
\hline $\mathrm{AD}$ & 4.4 & 0.7 & 4.7 & 0.5 & 4.8 & 0.6 & 4.9 & 0.3 & $<.001$ \\
\hline MD & 4.2 & 0.9 & 4.6 & 0.7 & 4.6 & 0.8 & 4.9 & 0.4 & $<.001$ \\
\hline
\end{tabular}

2 ROM: range of motion; IR: internal rotation; ER: external rotation; MMT: manual muscle testing; MT: middle

3 trapezius; MLT: middle and lower trapezius; RMM: rhomboid major and minor; SA: serratus anterior; LUT: upper

4 trapezius and levator scapular; AD: anterior deltoid and coracobrachialis; MD: middle deltoid and supraspinatus 


\section{Table 3 (on next page)}

Comparison of the ratio of the shoulder joint ROM and MMT between the neck-dissection side and the sound side. 
1 Table 3. Comparison of the ratio of the shoulder joint ROM and MMT between the neck-

2 dissection side and the sound side.

\begin{tabular}{|c|c|c|c|c|c|c|c|c|c|}
\hline \multirow[b]{2}{*}{$\square$} & \multicolumn{2}{|c|}{ Baseline } & \multicolumn{2}{|c|}{1 month } & \multicolumn{2}{|c|}{3 months } & \multicolumn{2}{|c|}{6 months } & \multirow{2}{*}{$\begin{array}{l}\mathrm{p} \text {-value } \\
\text { for trend }\end{array}$} \\
\hline & Mean & SD & Mean & SD & Mean & SD & Mean & SD & \\
\hline ROM & & & & & & & & & \\
\hline Flexion & .93 & .13 & .92 & .15 & .95 & .13 & .97 & .05 & .027 \\
\hline Abduction & .87 & .17 & .88 & .16 & .93 & .06 & .96 & .05 & $<.001$ \\
\hline IR & 1.06 & .21 & 1.06 & .12 & 1.02 & .14 & 1.02 & .13 & .101 \\
\hline ER & .97 & .11 & .99 & .06 & .96 & .08 & .98 & .07 & .467 \\
\hline MMT & & & & & & & & & \\
\hline MT & & & .93 & .15 & .94 & .10 & 1.00 & .16 & .012 \\
\hline MLT & & & .69 & .21 & .68 & .22 & .76 & .23 & .005 \\
\hline RMM & & & .97 & .08 & .99 & .03 & 1.00 & 0.00 & .025 \\
\hline SA & .93 & .17 & .90 & .14 & .92 & .12 & .98 & .07 & .240 \\
\hline LUT & .94 & .15 & .98 & .06 & .99 & .04 & 1.00 & 0.00 & .026 \\
\hline $\mathrm{AD}$ & .92 & .13 & .94 & .12 & .96 & .10 & .98 & .06 & .003 \\
\hline MD & .90 & .14 & .92 & .14 & .95 & .12 & .98 & .09 & $<.001$ \\
\hline
\end{tabular}

3 ROM: range of motion; IR: internal rotation; ER: external rotation; MMT: manual muscle testing; MT: middle

4 trapezius; MLT: middle and lower trapezius; RMM: rhomboid major and minor; SA: serratus anterior; LUT: upper 5 trapezius and levator scapular; AD: anterior deltoid and coracobrachialis; MD: middle deltoid and supraspinatus 6 


\section{Table 4(on next page)}

Overview of the EORTC QLQ-C30 scores in the whole model and group model. 
Table 4. Overview of the EORTC QLQ-C30 scores in the whole model and group model.

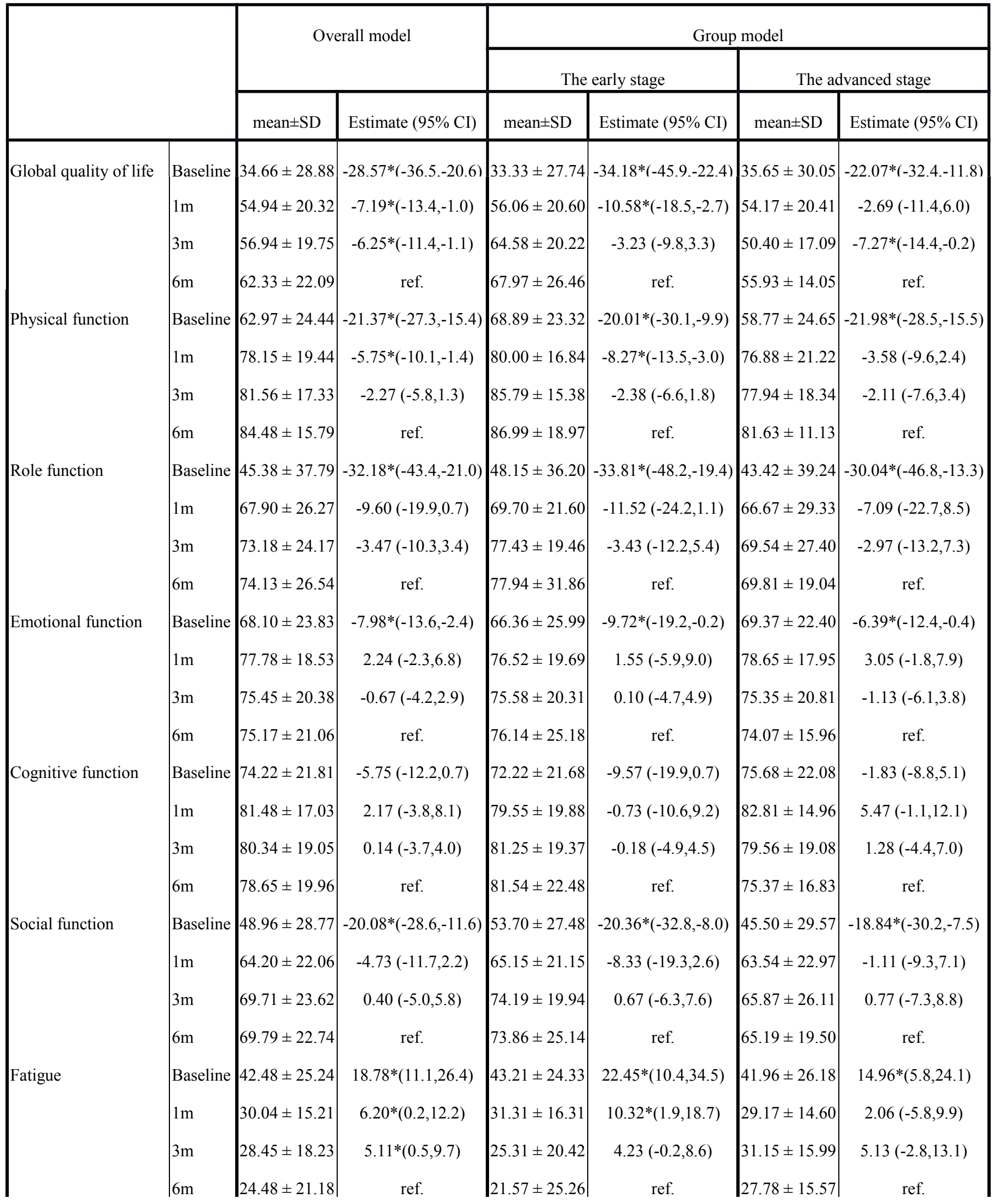




\begin{tabular}{|c|c|c|c|c|c|c|c|}
\hline \multirow[t]{4}{*}{ Nausea/vomiting } & Baseline & $13.85 \pm 19.22$ & $8.04 *(2.4,13.7)$ & $14.81 \pm 22.33$ & $9.23 *(0.7,17.8)$ & $13.16 \pm 16.96$ & $7.96 *(0.3,15.7)$ \\
\hline & $1 \mathrm{~m}$ & $8.33 \pm 18.24$ & $2.38(-2.5,7.3)$ & $2.27 \pm 7.79$ & $-3.64(-9.1,1.8)$ & $12.50 \pm 22.00$ & $7.32 *(0.3,14.3)$ \\
\hline & $3 \mathrm{~m}$ & $10.31 \pm 14.01$ & $4.92 *(0.5,9.3)$ & $5.32 \pm 12.09$ & $0.09(-6.2,6.4)$ & $14.58 \pm 14.32$ & $9.72 *(4.3,15.2)$ \\
\hline & $6 \mathrm{~m}$ & $5.64 \pm 11.41$ & ref. & $4.74 \pm 12.02$ & ref. & $6.67 \pm 11.00$ & ref. \\
\hline \multirow[t]{4}{*}{ Pain } & Baseline & $44.87 \pm 26.01$ & $22.48 *(14.0,31.0)$ & $45.68 \pm 20.46$ & $26.15 *(13.9,38.4)$ & $44.30 \pm 29.58$ & $18.55 *(7.5,29.6)$ \\
\hline & $1 \mathrm{~m}$ & $24.38 \pm 19.88$ & $1.92(-4.9,8.7)$ & $27.27 \pm 18.93$ & $7.89(-0.6,16.3)$ & $22.40 \pm 20.57$ & $-3.58(-12.6,5.5)$ \\
\hline & $3 \mathrm{~m}$ & $28.21 \pm 20.03$ & $5.63 *(0.2,11.1)$ & $25.12 \pm 20.84$ & $4.66(-1.8,11.1)$ & $30.85 \pm 19.28$ & $5.62(-3.0,14.2)$ \\
\hline & $6 \mathrm{~m}$ & $22.05 \pm 21.40$ & ref. & $19.93 \pm 24.93$ & ref. & $24.44 \pm 17.10$ & ref. \\
\hline \multirow[t]{4}{*}{ Dyspnea } & Baseline & $23.44 \pm 28.28$ & $12.73 *(4.7,20.8)$ & $20.99 \pm 20.98$ & $13.55 *(3.4,23.6)$ & $25.23 \pm 32.78$ & $13.76 *(1.3,26.2)$ \\
\hline & $1 \mathrm{~m}$ & $8.64 \pm 17.36$ & $-1.73(-6.5,3.1)$ & $7.58 \pm 17.61$ & $-0.10(-3.0,2.8)$ & $9.38 \pm 17.42$ & $-1.70(-9.8,6.4)$ \\
\hline & $3 \mathrm{~m}$ & $13.46 \pm 14.98$ & $2.70(-2.5,7.9)$ & $8.80 \pm 13.50$ & $0.70(-5.5,6.9)$ & $17.46 \pm 15.25$ & $5.61(-1.9,13.1)$ \\
\hline & $6 \mathrm{~m}$ & $10.94 \pm 17.25$ & ref. & $7.84 \pm 18.74$ & ref. & $14.44 \pm 15.26$ & ref. \\
\hline \multirow[t]{4}{*}{ Insomnia } & Baseline & $48.21 \pm 32.82$ & $24.28 *(14.5,34.1)$ & $46.91 \pm 33.66$ & $27.14 *(12.9,41.3)$ & $49.12 \pm 32.64$ & $20.26 *(6.4,34.1)$ \\
\hline & $1 \mathrm{~m}$ & $29.63 \pm 27.98$ & $4.39(-3.7,12.5)$ & $36.36 \pm 30.70$ & $14.98 *(4.9,25.0)$ & $25.00 \pm 25.40$ & $-4.98(-17.4,7.4)$ \\
\hline & $3 \mathrm{~m}$ & $28.21 \pm 23.75$ & $4.53(-1.6,10.7)$ & $25.93 \pm 21.34$ & $6.84 *(0.2,13.5)$ & $30.16 \pm 25.86$ & $1.34(-8.8,11.5)$ \\
\hline & $6 \mathrm{~m}$ & $25.35 \pm 27.83$ & ref. & $18.95 \pm 23.41$ & ref. & $32.59 \pm 31.35$ & ref. \\
\hline \multirow[t]{4}{*}{ Loss of appetite } & Baseline & $25.13 \pm 30.64$ & $10.00 *(0.2,19.8)$ & $28.40 \pm 32.95$ & $20.59 *(8.7,32.4)$ & $22.81 \pm 29.11$ & $-0.32(-15.5,14.8)$ \\
\hline & $1 \mathrm{~m}$ & $13.58 \pm 21.98$ & $-1.91(-9.4,5.5)$ & $10.61 \pm 18.93$ & $2.36(-3.6,8.4)$ & $15.63 \pm 23.92$ & $-7.88(-21.6,5.8)$ \\
\hline & $3 \mathrm{~m}$ & $20.09 \pm 19.96$ & $5.26(-1.7,12.2)$ & $14.35 \pm 17.49$ & $6.68 *(0.4,13.0)$ & $25.00 \pm 20.92$ & $2.37(-10.5,15.2)$ \\
\hline & $6 \mathrm{~m}$ & $15.63 \pm 23.59$ & ref. & $8.17 \pm 14.84$ & ref. & $24.07 \pm 28.92$ & ref. \\
\hline \multirow[t]{4}{*}{ Constipation } & Baseline & $20.00 \pm 26.87$ & $1.72(-6.1,9.6)$ & $18.52 \pm 28.24$ & $3.03(-4.3,10.3)$ & $21.05 \pm 26.19$ & $-0.02(-14.3,14.3)$ \\
\hline & $1 \mathrm{~m}$ & $16.05 \pm 23.11$ & $-3.31(-10.2,3.6)$ & $13.64 \pm 24.47$ & $-2.43(-7.8,3.0)$ & $17.71 \pm 22.38$ & $-4.47(-17.7,8.8)$ \\
\hline & $3 \mathrm{~m}$ & $19.23 \pm 21.88$ & $1.73(-3.3,6.8)$ & $14.12 \pm 19.45$ & $1.19(-3.8,6.2)$ & $23.61 \pm 23.21$ & $2.16(-7.2,11.6)$ \\
\hline & $6 \mathrm{~m}$ & $17.53 \pm 25.05$ & ref. & $14.38 \pm 22.74$ & ref. & $21.11 \pm 27.79$ & ref. \\
\hline \multirow[t]{4}{*}{ Diarrhea } & Baseline & $22.40 \pm 23.80$ & $7.65 *(0.6,14.7)$ & $27.16 \pm 26.21$ & $15.58 *(6.2,25.0)$ & $18.92 \pm 21.57$ & $-0.61(-10.6,9.4)$ \\
\hline & $1 \mathrm{~m}$ & $17.90 \pm 19.11$ & $3.55(-2.4,9.5)$ & $19.70 \pm 19.68$ & $8.67 *(1.0,16.3)$ & $16.67 \pm 18.93$ & $-2.64(-10.7,5.4)$ \\
\hline & $3 \mathrm{~m}$ & $11.75 \pm 15.39$ & $-2.83(-7.8,2.2)$ & $12.27 \pm 17.34$ & $0.57(-5.4,6.6)$ & $11.31 \pm 13.82$ & $-7.72 *(-15.2,-0.2)$ \\
\hline & $6 \mathrm{~m}$ & $13.89 \pm 15.90$ & ref. & $8.50 \pm 14.45$ & ref. & $20.00 \pm 15.69$ & ref. \\
\hline \multirow[t]{4}{*}{ Financial problems } & Baseline & $42.71 \pm 29.97$ & $11.54 *(1.0,22.0)$ & $35.80 \pm 29.13$ & $14.73 *(1.1,28.4)$ & $47.75 \pm 29.96$ & $8.10(-7.9,24.1)$ \\
\hline & $1 \mathrm{~m}$ & $32.72 \pm 30.02$ & $0.64(-8.9,10.2)$ & $21.21 \pm 24.22$ & $-0.38(-9.9,9.2)$ & $40.63 \pm 31.38$ & $0.09(-16.3,16.5)$ \\
\hline & $3 \mathrm{~m}$ & $25.21 \pm 26.00$ & $-6.03(-12.4,0.4)$ & $18.06 \pm 23.81$ & $-3.60(-11.5,4.3)$ & $31.35 \pm 26.63$ & $-8.72(-19.1,1.7)$ \\
\hline & $6 \mathrm{~m}$ & $30.56 \pm 31.80$ & ref. & $23.53 \pm 31.21$ & ref. & $38.52 \pm 31.60$ & ref. \\
\hline
\end{tabular}

$* \mathrm{p}<0.05$ 
ref.: reference group (the base for comparison) 


\section{Table 5 (on next page)}

Overview of the EORTC QLQ-H\&N35 scores in the whole model and group model. 
Table15. Overview of the EORTC QLQ-H\&N35 scores in the whole model and group model.

\begin{tabular}{|c|c|c|c|c|c|c|c|}
\hline & & \multirow{2}{*}{\multicolumn{2}{|c|}{ Overall model }} & \multicolumn{4}{|c|}{ Group model } \\
\hline & & & & \multicolumn{2}{|c|}{ The early stage } & \multicolumn{2}{|c|}{ The advanced stage } \\
\hline & & mean $\pm \mathrm{SD}$ & Estimate $(95 \% \mathrm{CI})$ & mean $\pm \mathrm{SD}$ & Estimate $(95 \% \mathrm{CI})$ & mean $\pm \mathrm{SD}$ & Estimate $(95 \% \mathrm{CI})$ \\
\hline \multirow[t]{4}{*}{ Oral pain } & Baseline & $41.28 \pm 27.03$ & $19.90 *(12.9,26.9)$ & $44.44 \pm 24.02$ & $24.18 *(14.6,33.8)$ & $38.96 \pm 29.14$ & $15.80 *(6.6,25.0)$ \\
\hline & $1 \mathrm{~m}$ & $23.15 \pm 14.27$ & $1.80(-3.0,6.6)$ & $25.76 \pm 13.83$ & $5.75(-1.3,12.8)$ & $21.35 \pm 14.50$ & $-1.90(-7.0,3.2)$ \\
\hline & $3 \mathrm{~m}$ & $28.39 \pm 18.29$ & $6.43 *(1.9,11.0)$ & $22.28 \pm 16.72$ & $1.72(-4.7,8.2)$ & $33.63 \pm 18.22$ & $9.98 *(4.8,15.2)$ \\
\hline & $6 \mathrm{~m}$ & $19.71 \pm 15.54$ & ref. & $18.06 \pm 19.02$ & ref. & $21.73 \pm 10.20$ & ref. \\
\hline \multirow[t]{4}{*}{ Swallowing } & Baseline & $56.21 \pm 28.19$ & $32.34 *(25.4,39.3)$ & $46.60 \pm 23.91$ & $28.12 *(18.2,38.0)$ & $63.21 \pm 29.29$ & $34.95 *(25.7,44.2)$ \\
\hline & $1 \mathrm{~m}$ & $27.47 \pm 19.67$ & $4.19(-1.0,9.4)$ & $26.14 \pm 17.12$ & $8.45 *(2.5,14.4)$ & $28.39 \pm 21.47$ & $0.67(-6.4,7.8)$ \\
\hline & $3 \mathrm{~m}$ & $32.48 \pm 22.87$ & $8.21 *(3.1,13.3)$ & $22.11 \pm 17.09$ & $2.43(-2.6,7.5)$ & $41.37 \pm 23.69$ & $12.91 *(5.0,20.8)$ \\
\hline & $6 \mathrm{~m}$ & $24.60 \pm 18.54$ & ref. & $20.18 \pm 21.15$ & ref. & $29.96 \pm 13.64$ & ref. \\
\hline \multirow[t]{4}{*}{ Senses } & Baseline & $27.34 \pm 31.90$ & $9.02 *(0.7,17.4)$ & $22.84 \pm 28.17$ & $9.28(-2.5,21.0)$ & $30.63 \pm 34.36$ & $8.56(-3.9,21.0)$ \\
\hline & $1 \mathrm{~m}$ & $13.58 \pm 19.17$ & $-4.44(-11.4,2.5)$ & $11.36 \pm 19.51$ & $-2.86(-11.5,5.8)$ & $15.10 \pm 19.10$ & $-5.58(-17.0,5.8)$ \\
\hline & $3 \mathrm{~m}$ & $25.53 \pm 21.61$ & $6.97 *(0.8,13.2)$ & $15.86 \pm 15.44$ & $2.47(-4.6,9.5)$ & $33.83 \pm 22.89$ & $10.71 *(0.4,21.0)$ \\
\hline & $6 \mathrm{~m}$ & $18.10 \pm 23.97$ & ref. & $13.07 \pm 20.43$ & ref. & $24.21 \pm 27.18$ & ref. \\
\hline \multirow[t]{4}{*}{ Speech } & Baseline & $52.43 \pm 30.70$ & $25.93 *(17.1,34.8)$ & $48.56 \pm 26.36$ & $26.36 *(13.2,39.5)$ & $55.26 \pm 33.59$ & $24.72 *(13.0,36.4)$ \\
\hline & $1 \mathrm{~m}$ & $29.42 \pm 20.83$ & $4.18(-2.3,10.7)$ & $31.31 \pm 20.75$ & $9.26 *(0.7,17.8)$ & $28.13 \pm 21.12$ & $-0.20(-9.0,8.6)$ \\
\hline & $3 \mathrm{~m}$ & $33.26 \pm 25.06$ & $6.21 *(0.6,11.8)$ & $25.39 \pm 17.42$ & $2.62(-4.8,10.1)$ & $40.01 \pm 28.73$ & $8.81 *(1.0,16.6)$ \\
\hline & $6 \mathrm{~m}$ & $26.58 \pm 24.30$ & ref. & $22.66 \pm 25.45$ & ref. & $31.35 \pm 22.81$ & ref. \\
\hline \multirow[t]{4}{*}{ Social eating } & Baseline & $50.39 \pm 32.71$ & $14.08 *(5.8,22.4)$ & $47.84 \pm 32.08$ & $15.97 *(2.9,29.1)$ & $52.25 \pm 33.49$ & $11.87 *(2.3,21.4)$ \\
\hline & $1 \mathrm{~m}$ & $33.33 \pm 26.35$ & $-2.33(-8.5,3.8)$ & $35.23 \pm 29.87$ & $1.22(-6.8,9.2)$ & $32.03 \pm 24.05$ & $-6.01(-14.1,2.1)$ \\
\hline & $3 \mathrm{~m}$ & $37.34 \pm 27.16$ & $1.47(-3.2,6.1)$ & $32.99 \pm 24.83$ & $-0.19(-6.3,5.9)$ & $41.07 \pm 28.93$ & $2.26(-4.3,8.8)$ \\
\hline & $6 \mathrm{~m}$ & $36.51 \pm 24.37$ & ref. & $33.50 \pm 30.21$ & ref. & $40.18 \pm 14.85$ & ref. \\
\hline \multirow[t]{4}{*}{ Social contact } & Baseline & $43.44 \pm 29.07$ & $14.93 *(6.3,23.5)$ & $39.26 \pm 24.34$ & $14.95 *(2.7,27.2)$ & $46.49 \pm 32.07$ & $14.62 *(2.7,26.5)$ \\
\hline & $1 \mathrm{~m}$ & $28.40 \pm 22.40$ & $-0.68(-7.2,5.8)$ & $30.00 \pm 23.44$ & $3.49(-5.5,12.5)$ & $27.29 \pm 21.97$ & $-4.10(-13.2,5.0)$ \\
\hline & $3 \mathrm{~m}$ & $30.67 \pm 24.38$ & $2.67(-3.5,8.8)$ & $27.38 \pm 21.67$ & $3.11(-4.4,10.6)$ & $33.49 \pm 26.55$ & $2.25(-7.4,11.9)$ \\
\hline & $6 \mathrm{~m}$ & $28.61 \pm 20.88$ & ref. & $26.40 \pm 22.38$ & ref. & $30.72 \pm 19.62$ & ref. \\
\hline \multirow[t]{4}{*}{ Sexuality } & Baseline & $39.32 \pm 35.68$ & $12.24 *(3.2,21.3)$ & $34.57 \pm 27.71$ & $12.26(-0.5,25.0)$ & $42.79 \pm 40.55$ & $10.85(-1.5,23.2)$ \\
\hline & $1 \mathrm{~m}$ & $29.94 \pm 26.77$ & $2.10(-6.1,10.3)$ & $31.06 \pm 26.38$ & $6.24(-2.3,14.7)$ & $29.17 \pm 27.44$ & $-2.52(-15.4,10.4)$ \\
\hline & $3 \mathrm{~m}$ & $33.07 \pm 29.03$ & $5.77(-0.2,11.7)$ & $28.01 \pm 26.58$ & $4.73(-3.0,12.5)$ & $37.40 \pm 30.79$ & $5.51(-3.6,14.6)$ \\
\hline & $6 \mathrm{~m}$ & $29.57 \pm 29.65$ & ref. & $24.02 \pm 33.58$ & ref. & $36.31 \pm 23.48$ & ref. \\
\hline \multirow[t]{4}{*}{ Teeth } & Baseline & $46.03 \pm 36.13$ & $5.86(-5.8,17.5)$ & $41.98 \pm 30.09$ & $5.75(-8.0,19.5)$ & $49.07 \pm 40.23$ & $5.33(-13.5,24.2)$ \\
\hline & $1 \mathrm{~m}$ & $37.65 \pm 32.41$ & $-2.85(-13.0,7.3)$ & $42.42 \pm 31.17$ & $5.86(-5.6,17.3)$ & $34.38 \pm 33.32$ & $-9.75(-26.2,6.7)$ \\
\hline & $3 \mathrm{~m}$ & $40.71 \pm 26.83$ & $-0.47(-8.8,7.9)$ & $33.33 \pm 24.08$ & $-5.34(-14.2,3.6)$ & $47.02 \pm 27.86$ & $3.22(-11.2,17.6)$ \\
\hline & $6 \mathrm{~m}$ & $43.37 \pm 33.62 \mid$ & ref. & $40.52 \pm 34.79$ & ref. & $|46.83 \pm 33.10|$ & ref. \\
\hline
\end{tabular}




\begin{tabular}{|c|c|c|c|c|c|c|c|}
\hline \multirow[t]{4}{*}{ Opening mouth } & Baseline & $51.56 \pm 34.60$ & $20.97 *(12.0,29.9)$ & $48.15 \pm 32.47$ & $25.05 *(12.1,38.0)$ & $54.05 \pm 36.30$ & $14.51 *(3.2,25.8)$ \\
\hline & $1 \mathrm{~m}$ & $37.04 \pm 30.83$ & $6.69(-1.7,15.1)$ & $40.91 \pm 32.42$ & $18.96 *(7.6,30.3)$ & $34.38 \pm 29.92$ & $-5.52(-15.6,4.5)$ \\
\hline & $3 \mathrm{~m}$ & $36.43 \pm 24.64$ & $4.94(-1.1,10.9)$ & $34.03 \pm 23.07$ & $9.05 *(1.6,16.5)$ & $38.49 \pm 26.14$ & $-1.15(-9.5,7.3)$ \\
\hline & $6 \mathrm{~m}$ & $32.08 \pm 27.51$ & ref. & $23.86 \pm 26.99$ & ref. & $42.06 \pm 25.57$ & ref. \\
\hline \multirow[t]{4}{*}{ Dry mouth } & Baseline & $42.71 \pm 29.97$ & $4.93(-6.6,16.4)$ & $44.44 \pm 30.66$ & $18.64 *(4.3,33.0)$ & $41.44 \pm 29.82$ & $-10.77(-25.0,3.5)$ \\
\hline & $1 \mathrm{~m}$ & $31.48 \pm 22.82$ & $-6.51(-17.4,4.4)$ & $37.88 \pm 23.67$ & $12.10(-2.0,26.2)$ & $27.08 \pm 21.48$ & $-25.49 *(-37.1,-13.9)$ \\
\hline & $3 \mathrm{~m}$ & $39.85 \pm 23.54$ & $1.04(-6.7,8.8)$ & $33.33 \pm 21.17$ & $6.14(-2.7,15.0)$ & $45.44 \pm 24.38$ & $-7.35(-18.8,4.1)$ \\
\hline & $6 \mathrm{~m}$ & $39.61 \pm 32.10$ & ref. & $28.43 \pm 33.79$ & ref. & $53.17 \pm 24.72$ & ref. \\
\hline \multirow[t]{4}{*}{ Sticky saliva } & Baseline & $50.52 \pm 35.13$ & $18.25 *(7.0,29.5)$ & $49.38 \pm 36.25$ & $21.47 *(6.7,36.3)$ & $51.35 \pm 34.78$ & $15.50(-1.2,32.2)$ \\
\hline & $1 \mathrm{~m}$ & $30.86 \pm 23.21$ & $-1.24(-11.5,9.1)$ & $27.27 \pm 19.62$ & $-0.49(-14.1,13.1)$ & $33.33 \pm 25.40$ & $-2.33(-17.6,12.9)$ \\
\hline & $3 \mathrm{~m}$ & $40.71 \pm 27.65$ & $8.32 *(0.0,16.6)$ & $28.47 \pm 24.37$ & $-0.21(-9.3,8.9)$ & $51.19 \pm 26.29$ & $15.50 *(2.4,28.6)$ \\
\hline & $6 \mathrm{~m}$ & $31.72 \pm 29.99$ & ref. & $28.76 \pm 32.65$ & ref. & $35.32 \pm 27.18$ & ref. \\
\hline \multirow[t]{4}{*}{ Coughing } & Baseline & $46.88 \pm 27.68$ & $25.39 *(17.7,33.1)$ & $39.51 \pm 22.72$ & $25.07 *(13.8,36.4)$ & $52.25 \pm 29.96$ & $24.25 *(14.7,33.8)$ \\
\hline & $1 \mathrm{~m}$ & $25.93 \pm 24.80$ & $4.58(-2.3,11.4)$ & $21.21 \pm 16.41$ & $6.55(-3.5,16.6)$ & $29.17 \pm 29.02$ & $1.73(-5.8,9.3)$ \\
\hline & $3 \mathrm{~m}$ & $30.45 \pm 21.09$ & $9.38 *(3.8,15.0)$ & $22.92 \pm 15.40$ & $8.38 *(1.1,15.7)$ & $36.90 \pm 23.34$ & $9.45 *(1.4,17.5)$ \\
\hline & $6 \mathrm{~m}$ & $19.18 \pm 16.22$ & ref. & $13.73 \pm 16.91$ & ref. & $25.79 \pm 13.00$ & ref. \\
\hline \multirow[t]{4}{*}{ Feeling ill } & Baseline & $57.81 \pm 92.44$ & $28.78 *(6.9,50.6)$ & $71.60 \pm 136.41$ & $41.73(-7.8,91.3)$ & $47.75 \pm 35.61$ & $21.61 *(9.9,33.4)$ \\
\hline & $1 \mathrm{~m}$ & $26.54 \pm 25.39$ & $-1.45(-8.6,5.7)$ & $31.82 \pm 26.18$ & $3.26(-6.6,13.2)$ & $22.92 \pm 24.59$ & $-2.32(-12.1,7.4)$ \\
\hline & $3 \mathrm{~m}$ & $34.62 \pm 22.32$ & $5.09(-1.1,11.3)$ & $32.41 \pm 20.96$ & $2.12(-5.4,9.6)$ & $36.51 \pm 23.64$ & $9.86 *(0.9,18.8)$ \\
\hline & $6 \mathrm{~m}$ & $29.03 \pm 20.47$ & ref. & $29.08 \pm 27.18$ & ref. & $28.97 \pm 7.60$ & ref. \\
\hline
\end{tabular}

$* \mathrm{p}<0.08$

ref.: refßrence group (the base for comparison)

4

5

6 